\title{
Influence of the preparation method on the photocatalytic activity of $\mathrm{Nd}$-modified $\mathrm{TiO}_{2}$
}

\author{
Patrycja Parnicka1, Paweł Mazierski ${ }^{1}$, Tomasz Grzyb², Wojciech Lisowski ${ }^{3}$, \\ Ewa Kowalska ${ }^{4}$, Bunsho Ohtani ${ }^{4}$, Adriana Zaleska-Medynska ${ }^{* 1}$ and Joanna Nadolna*1
}

\section{Full Research Paper}

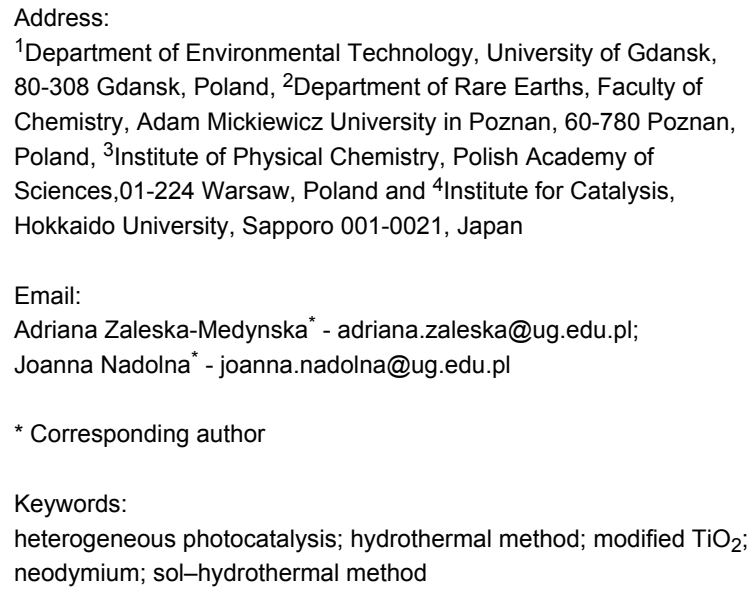

${ }^{1}$ Department of Environmental Technology, University of Gdansk, 80-308 Gdansk, Poland, ${ }^{2}$ Department of Rare Earths, Faculty of Chemistry, Adam Mickiewicz University in Poznan, 60-780 Poznan, Poland, ${ }^{3}$ Institute of Physical Chemistry, Polish Academy of Sciences, 01-224 Warsaw, Poland and ${ }^{4}$ Institute for Catalysis, Hokkaido University, Sapporo 001-0021, Japan

Email:

Adriana Zaleska-Medynska* - adriana.zaleska@ug.edu.pl;

Joanna Nadolna* - joanna.nadolna@ug.edu.pl

* Corresponding author

Keywords:

heterogeneous photocatalysis; hydrothermal method; modified $\mathrm{TiO}_{2}$; neodymium; sol-hydrothermal method

Beilstein J. Nanotechnol. 2018, 9, 447-459.

doi:10.3762/bjnano.9.43

Received: 29 September 2017

Accepted: 08 January 2018

Published: 06 February 2018

This article is part of the Thematic Series "Energy conversion, storage and environmental remediation using nanomaterials".

Guest Editor: W.-J. Ong

(C) 2018 Parnicka et al.; licensee Beilstein-Institut. License and terms: see end of document.

\begin{abstract}
Nd-modified $\mathrm{TiO}_{2}$ photocatalysts have been obtained via hydrothermal (HT) and sol-hydrothermal (SHT) methods. The as-prepared samples were characterized by X-ray diffraction (XRD), BET surface area measurements, scanning electron microscopy (SEM), diffuse reflectance spectroscopy (DRS), luminescence spectroscopy and X-ray photoelectron spectroscopy (XPS). The photocatalytic activity of the synthesized samples was evaluated by the degradation of phenol in aqueous solution under irradiation with UV-vis $(\lambda>350 \mathrm{~nm})$ and vis $(\lambda>420 \mathrm{~nm})$ light, as well as by the degradation of gaseous toluene under irradiation with vis $\left(\lambda_{\max }=415 \mathrm{~nm}\right)$ light. It was found that $\mathrm{Nd}$-modified $\mathrm{TiO}_{2}$ is an efficient photocatalyst for the degradation of phenol and toluene under visible light. XPS analysis revealed that the photocatalyst prepared via HT method contains a three-times higher amount of hydroxy groups at the surface layer and a two-times higher amount of surface defects than that obtained by the SHT method. The photocatalytic efficiency of phenol and toluene degradation under vis irradiation in the presence of $0.25 \% \mathrm{Nd}_{-} \mathrm{TiO} \mathrm{O}_{2}(\mathrm{HT}) \mathrm{reached}$ 0.62 and $3.36 \mu \mathrm{mol} \cdot \mathrm{dm}^{-1} \cdot \mathrm{min}^{-1}$, respectively. Photocatalytic activity tests in the presence of $\mathrm{Nd}-\mathrm{TiO}_{2}$ and scavenger confirm that superoxide radicals were responsible for the visible light-induced degradation of the model pollutant in aqueous solution.
\end{abstract}

\section{Introduction}

Heterogeneous photocatalysis based on titanium dioxide $\left(\mathrm{TiO}_{2}\right)$ has become the focus of numerous studies due to its possible applications in the treatment of air, water and wastewater [1-5] after the photocatalytic splitting of water on $\mathrm{TiO}_{2}$ electrodes was discovered by Fujishima and Honda in 1972 [6]. However, serious disadvantages of $\mathrm{TiO}_{2}$ are its wide band gap, which 
requires the use of ultraviolet light irradiation for excitation (the band gap of anatase is about $3.2 \mathrm{eV}$ ) and low quantum yield (due to the fast recombination of electron-hole pairs) [7]. These restrictions on its application could be overcome by modifying $\mathrm{TiO}_{2}$, which results in increased activity and ability to work under visible light irradiation [8-10].

In recent years, the modification with rare earth (RE) metals has proven to be an efficient method to improve the photocatalytic properties of $\mathrm{TiO}_{2}$ and to broaden its absorption to the solar spectrum $[8,11,12]$. Various Lewis bases can form complexes with RE-modified $\mathrm{TiO}_{2}$, which leads to enhanced surface adsorption properties of $\mathrm{TiO}_{2}$ and indirectly increases the photocatalytic activity of the photocatalysts $[13,14]$. Moreover, it has been reported that the presence of RE ions slowed down the rate of the charge-carrier recombination processes [15] Besides, RE ions, due to the $4 \mathrm{f}$ electron structure, can act as conversion luminescent media $[14,16-18]$. Neodymium $\left(\mathrm{Nd}^{3+}\right)$ ions are well known as one of the more interesting lanthanides due to unique electronic and optical properties [19,20]. Several reports suggested that the transformation of light from near-infrared and visible spectral ranges into ultraviolet wavelengths can be responsible for the photocatalytic activity of RE-modified $\mathrm{TiO}_{2}$ [21,22]. In our previous paper, based on action spectra analysis we revealed that $\mathrm{Nd}$-modified $\mathrm{TiO}_{2}$ could be excited under visible light in the range of 400 to $480 \mathrm{~nm}$. Nevertheless, it has been proven that the up-conversion process was not responsible for the degradation of phenol under vis irradiation [23]. A similar conclusion based on action spectra analysis was also formulated by us for other $\mathrm{RE}-\mathrm{TiO}_{2}$ systems activated by visible light $[11,14,24]$.

The photocatalytic activity is strictly affected by physical properties such as crystalline structure and size, specific surface area, and the density of surface hydroxy groups [7]. The impact of the synthesis of $\mathrm{TiO}_{2}$ nanoparticles (NPs) on properties and morphology is important for understanding, creating and improving materials for various applications. According to the literature, RE-modified $\mathrm{TiO}_{2}$ could be prepared through a wide spectrum of methods, such as sol-gel [18,25], hydrothermal [23,26,27], solvothermal [28], electrospinning [29], co-precipitation [30] and electrochemical [8] methods.
In our previous papers, we presented experimental studies concerning the effect of synthesis methods on lanthanide-modified $\mathrm{TiO}_{2}$. In these studies we compared hydrothermal and sol-gel method. The synthesis method significantly affects the structure, optical, luminescence and photocatalytic properties. It was found that all samples $\left(\mathrm{TiO}_{2}\right.$ modified with $\mathrm{Y}^{3+}, \mathrm{Pr}^{3+}, \mathrm{Er}^{3+}$ and $\mathrm{Eu}^{3+}$ ) obtained through the hydrothermal method approach exhibited a higher photocatalytic activity, while the samples prepared via the sol-gel method approach yielded more luminescence when irradiated with $980 \mathrm{~nm}$ photons [24].

Meanwhile, the hydrothermal treatments in combination with the sol-gel method (sol-hydrothermal method) provide an alternative approach for preparing $\mathrm{TiO}_{2}$. During the preparation, before the hydrothermal process, a sol is obtained, which may prevent the agglomeration of the nanocrystals [26]. However, information regarding the photocatalytic activity of Nd-modified $\mathrm{TiO}_{2}$ NPs preparated by the sol-hydrothermal method is still lacking in the literature.

In view of this, in the present study, we proposed to combine the effects of synthesis route and neodymium modification to improve the photocatalytic activity of $\mathrm{TiO}_{2}$ under visible light. The Nd-modified $\mathrm{TiO}_{2}$ photocatalysts have been prepared using two different preparation routes, namely hydrothermal and sol-hydrothermal methods. The surface properties of these photocatalysts have been correlated with the preparation method as well as with the photoactivity in two model reactions, degradation of phenol in aqueous solution and degradation of gaseous toluene. Moreover, the photocatalytic mechanism of the Nd-modified photocatalysts was explored using a scavenger test.

\section{Results and Discussion}

Table 1 contains the description of all prepared photocatalysts, including preparation method, content of $\mathrm{Nd}$, BET surface area and crystallite sizes. The amount of $\mathrm{Nd}$ precursor $(0.25 \mathrm{~mol} \%)$ was selected based on previous research $[10,24]$.

\section{Structural properties}

The X-ray diffraction (XRD) technique was used to determined the crystalline phase of pristine $\mathrm{TiO}_{2}$ and Nd-modified $\mathrm{TiO}_{2}$

\begin{tabular}{|c|c|c|c|c|}
\hline sample label & preparation method & content of $\mathrm{Nd}(\mathrm{mol} \%)$ & $S_{\text {BET }}\left(\mathrm{m}^{2} / \mathrm{g}\right)$ & crystallite size (nm) \\
\hline pristine- $\mathrm{TiO}_{2}(\mathrm{SHT})$ & sol-hydrothermal & 0 & 106 & 16.3 \\
\hline $0.25 \% \mathrm{Nd}-\mathrm{TiO}_{2}(\mathrm{SHT})$ & sol-hydrothermal & 0.25 & 137 & 14.3 \\
\hline pristine- $\mathrm{TiO}_{2}(\mathrm{HT})$ & hydrothermal & 0 & 117 & 8.9 \\
\hline $0.25 \% \mathrm{Nd}-\mathrm{TiO}_{2}(\mathrm{HT})$ & hydrothermal & 0.25 & 126 & 7.4 \\
\hline
\end{tabular}


NPs. The XRD patterns of the examined samples are shown in Figure 1. In all synthesized photocatalysts, the diffraction pattern presents a group of lines at $2 \theta$ values of 25.4, 37.9, 48.1, $54.1,55.1$ and $62.9^{\circ}$, which are characteristic of anatase phase. The phase transformation to rutile has not occurred despite the heat treatment at $450{ }^{\circ} \mathrm{C}$. The absence of peaks corresponding to $\mathrm{Nd}_{2} \mathrm{O}_{3}$ in the XRD patterns can be ascribed to the following phenomena: The content of $\mathrm{Nd}^{3+}$ ions was too small or highly dispersed and was below the detection limit of the diffractometer, $\mathrm{Nd}^{3+}$ was present in the form of an amorphous phase or $\mathrm{Nd}^{3+}$ ions adsorbed either on the titania surface or $\mathrm{Nd}^{3+}$ cations were placed inside the titania lattice (titania doping) [24,31].

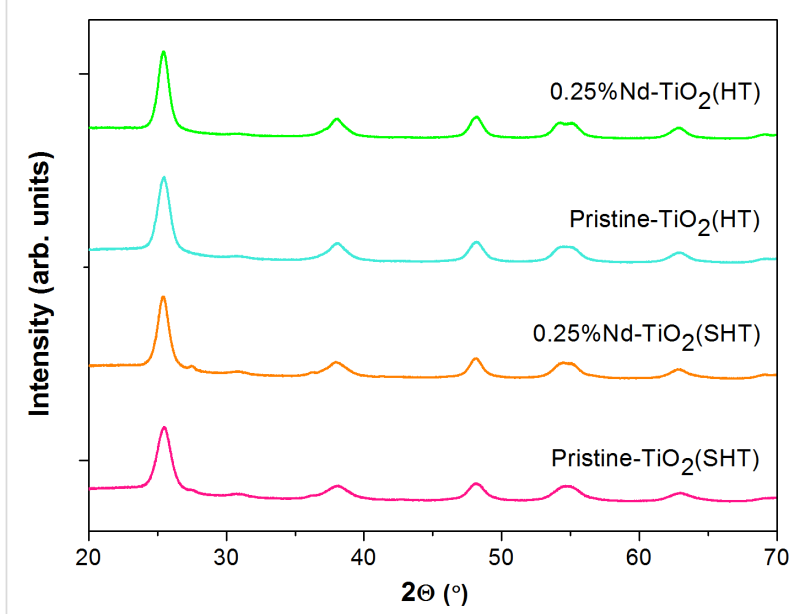

Figure 1: X-ray diffraction patterns of pristine $\mathrm{TiO}_{2}$ and $\mathrm{Nd}$-modified $\mathrm{TiO}_{2}$ prepared by sol-hydrothermal and hydrothermal methods.

Using the Scherrer equation, the average crystallite size of anatase was determined and presented in Table 1. For modified samples, $0.25 \% \mathrm{Nd}^{-\mathrm{TiO}_{2}}(\mathrm{SHT})$ and $0.25 \% \mathrm{Nd}-\mathrm{TiO}_{2}(\mathrm{HT})$ the crystallite sizes were 14.3 and $7.4 \mathrm{~nm}$, respectively. While, for pristine samples, pristine- $\mathrm{TiO}_{2}(\mathrm{SHT})$ and pristine- $\mathrm{TiO}_{2}(\mathrm{HT})$ the crystallite sizes were equal to 16.3 and $8.9 \mathrm{~nm}$, respectively. This indicates that the neodymium ions can inhibit the growth of crystallite size of $\mathrm{TiO}_{2}$. The photocatalysts prepared by the hydrothermal method showed a higher contraction of crystallites than those obtained by the sol-hydrothermal method. The present study reveals that loading with neodymium ions hindered the increase in grain size of $\mathrm{TiO}_{2}$ during hydrothermal synthesis. Our findings correlate with some other reports. A similar average particle size of anatase (compared to the HT samples) was observed by Thomas and co-workers [31]. In their study, NPs of $\mathrm{Nd}^{-\mathrm{TiO}_{2}}$ were prepared by using titanium(IV) isopropoxide and $\mathrm{NdCl}_{3}$ as the titanium and neodymium source in the hydrothermal reaction at $180^{\circ} \mathrm{C}$ for $2 \mathrm{~h}$. The surface area of all as-prepared samples ranged from 106 to $137 \mathrm{~m}^{2} / \mathrm{g}$
(Table 1). All Nd-modified photocatalysts showed higher BET surface area than the pristine samples. The highest BET surface area was observed for the $0.25 \% \mathrm{Nd}-\mathrm{TiO}_{2}(\mathrm{SHT})$ sample. According to literature data and our previous investigation, the presence of lanthanides in the obtained samples contributed to a decrease in size of the crystallites, which probably caused an increase in the specific surface area of photocatalysts $[24,32,33]$.

The difference in ion radii $\left(0.99 \AA\right.$ for $\mathrm{Nd}^{3+}$ and $0.75 \AA$ for $\mathrm{Ti}^{4+}$ ) suggests that $\mathrm{Nd}^{3+}$ ions cannot be effectively incorporated into the $\mathrm{TiO}_{2}$ lattice. Additionally, a full inclusion of $\mathrm{Nd}^{3+}$ ions may be hindered by the low coordination number of $\mathrm{Ti}^{4+}$ ions $(\mathrm{CN}=6)$, because $\mathrm{Nd}^{3+}$ ions prefer sites with $\mathrm{CN}=8$ or 9 . Therefore, it is reasonable to assume that Nd-containing species are localized at the surface of $\mathrm{TiO}_{2}$ [34]. Xie et al. [35] have reported that during the hydrothermal reaction, $\mathrm{Nd}^{3+}$ and $\mathrm{O}^{2-}$ ions could form a Nd-O oxide on the superficial layer of the $\mathrm{TiO}_{2}$ particle by a chemical bonding process and $\mathrm{Nd}^{3+}$ ions mainly occur in the form of $\mathrm{Ti}-\mathrm{O}-\mathrm{Nd}$ in the $\mathrm{Nd}_{-} \mathrm{TiO}_{2}$ compound. The formation of $\mathrm{Ti}-\mathrm{O}-\mathrm{Nd}$ bonds probably restricts direct contact between $\mathrm{TiO}_{2}$ crystallites and stabilizes the anatase phase and crystallite growth $[25,35]$.

\section{Morphology}

Surface morphology of the obtained photocatalysts was studied using scanning electron microscopy (SEM). Figure 2 shows a SEM image of pristine $\mathrm{TiO}_{2}$ and Nd-modified $\mathrm{TiO}_{2}$, and an irregular shape of particles can be clearly observed. Moreover, aggregation occurred in all samples. These images show no change in particle morphology due to Nd loading. The shape of particles does not show much difference between the synthesis methods. However, it seems that for photocatalysts obtained by the SHT method the agglomerates are a bit smaller.

\section{Optical and photoluminescence properties}

To study the optical absorption properties of the as-prepared photocatalysts, diffuse reflectance spectra (DRS) in the range of 200-850 $\mathrm{nm}$ were investigated, and the results are shown in Figure 3.

The optical absorption of $\mathrm{TiO}_{2}$ in the UV region below $400 \mathrm{~nm}$ can be mainly attributed to the charge transfer, related to electron excitation from the valence band to the conduction band (band-to-band transition, $\mathrm{O}_{2 \mathrm{p}} \rightarrow \mathrm{Ti}_{3 \mathrm{~d}}$ ) [30]. Modification of $\mathrm{TiO}_{2}$ with neodymium significantly affected the light absorption of the photocatalysts. A redshift of the absorption edge toward the visible region was observed for the Nd-modified samples. The optical absorption edge was shifted further when the SHT method was applied. Nassuko et al. reported that the redshift can be ascribed to the new energy level in the band gap and 

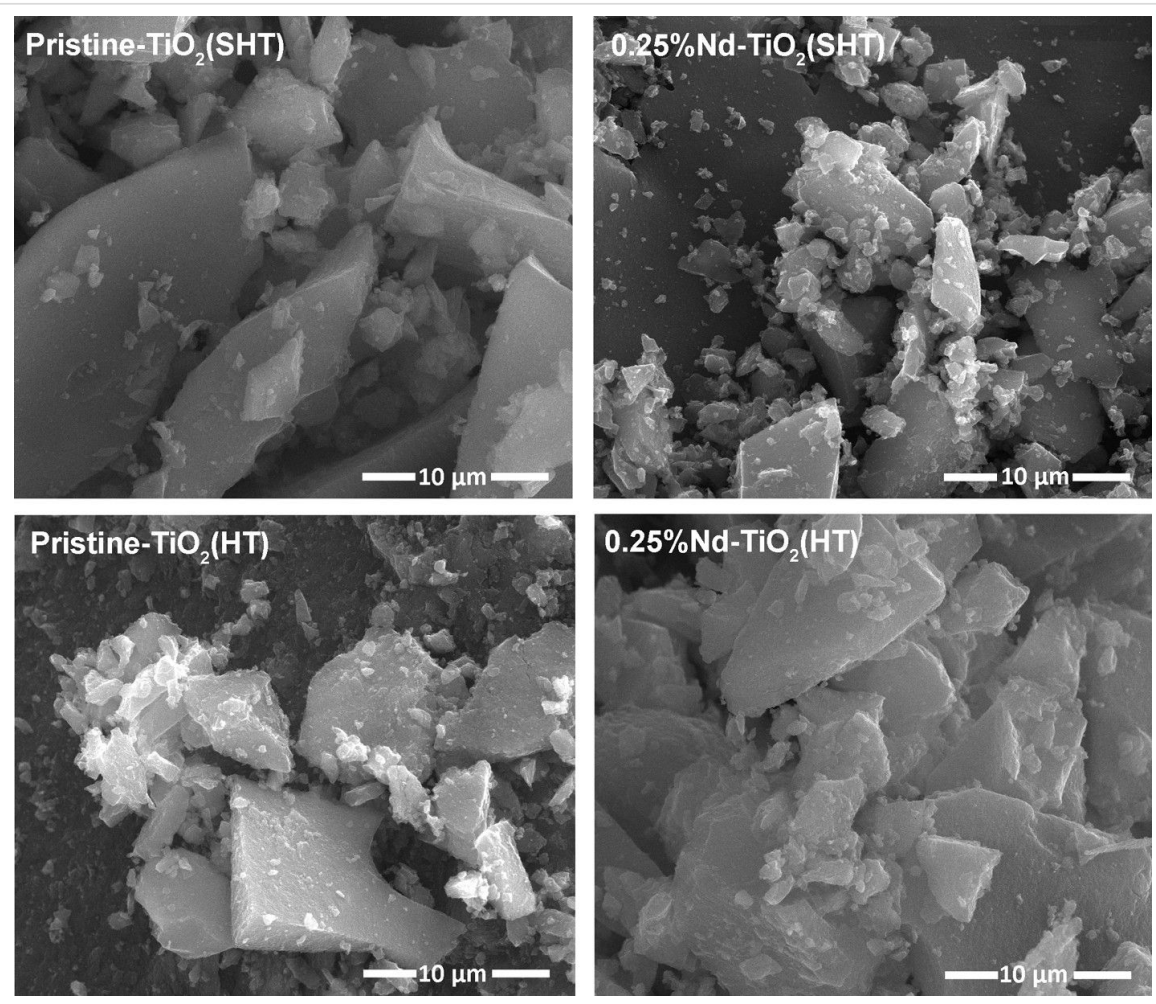

Figure 2: $\mathrm{SEM}$ images of $\mathrm{TiO}_{2}$ and $\mathrm{Nd}$-modified $\mathrm{TiO}_{2}$.

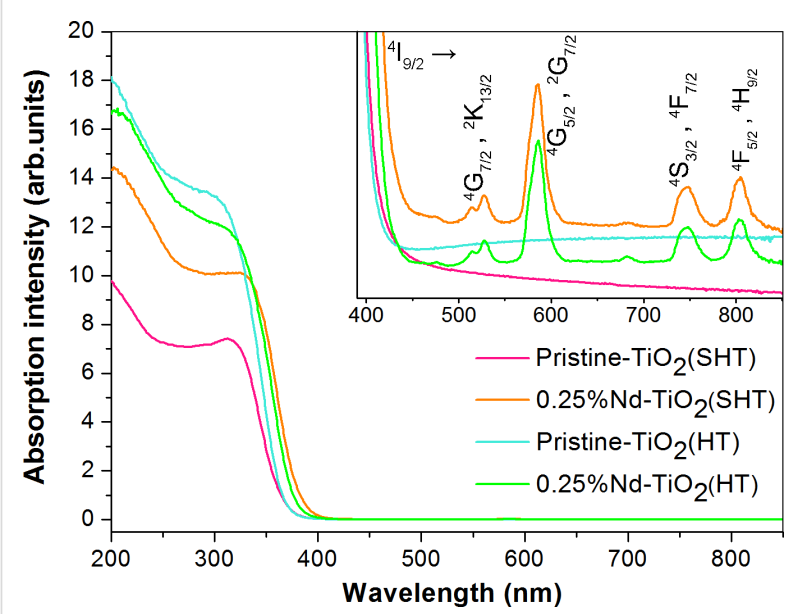

Figure 3: UV-vis diffuse reflectance spectra of $\mathrm{Nd}$-modified $\mathrm{TiO}_{2}$ photocatalysts and pristine $\mathrm{TiO}_{2}$.

charge transfer between the $\mathrm{TiO}_{2}$ valence band and $\mathrm{Nd}^{3+}$ ion levels [36]. Furthermore, there are four absorption bands in the vis region typical for neodymium located at 520, 585, 745 and $805 \mathrm{~nm}$. They correspond to transitions from the ${ }^{4} \mathrm{I}_{9 / 2}$ ground state to the excited states of ${ }^{4} \mathrm{G}_{7 / 2}$ and ${ }^{2} \mathrm{~K}_{13 / 2},{ }^{4} \mathrm{G}_{5 / 2}$ and ${ }^{2} \mathrm{G}_{7 / 2}$, ${ }^{4} \mathrm{~S}_{3 / 2}$ and ${ }^{4} \mathrm{~F}_{7 / 2},{ }^{4} \mathrm{~F}_{5 / 2}$ and ${ }^{2} \mathrm{H}_{9 / 2}$ [30,37]. In all of the studied $\mathrm{Nd}$-modified samples, the intensity of these absorption bands was similar.
To understand the rate of electron-hole recombination, photoluminescence (PL) spectroscopy was applied. Figure 4 shows the PL spectra of pristine and Nd-modified $\mathrm{TiO}_{2}$ under excitation by light at $\lambda_{\mathrm{ex}}=315 \mathrm{~nm}$.

The photoluminescence spectra show a weak broad emission band with a maximum intensity at around $350-700 \mathrm{~nm}$. Khalid et al. [38] and Raja et al. [39] reported that emission in that

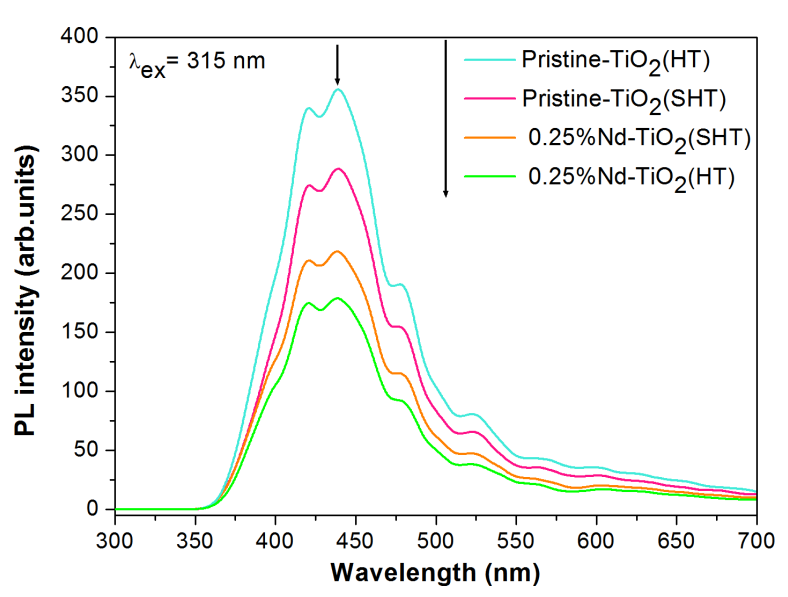

Figure 4: Photoluminescence spectra under UV light $\left(\lambda_{\mathrm{ex}}=315 \mathrm{~nm}\right)$ of pristine $\mathrm{TiO}_{2}$ and $\mathrm{Nd}$-modified $\mathrm{TiO}_{2}$ prepared by sol-hydrothermal and hydrothermal methods. 
range is characteristic for direct (band-band) or indirect (via a band-gap state) recombination of excited electrons and holes [38]. The $\mathrm{Nd}-\mathrm{TiO}_{2}$ photocatalysts were characterized by a better separation ability of the photogenerated electrons and holes compared to pristine samples. In addition, the Nd-modified photocatalyst prepared by the HT method exhibited the lowest photoluminescence intensity, which suggests that the prepared material significantly inhibited the recombination of photogenerated charge carriers, which can improve the photocatalytic performance. A possible reason is the occurrence of numerous $\mathrm{Ti}-\mathrm{O}-\mathrm{Nd}$ bonds increasing the content of surface oxygen vacancies and defects $[31,40]$. These electron trapping sites can enhance the separation of photogenerated electron-hole pairs [24]. Furthermore, both pristine and $\mathrm{Nd}-\mathrm{TiO}_{2} \mathrm{NPs}$ exhibit obvious excitonic PL signals with a similar curve shape. The observed phenomena can be explained by the spectroscopic properties of the $\mathrm{Nd}^{3+}$ ions caused by the transition of electrons within the $4 \mathrm{f}$ subshell and the shielding properties of the $5 \mathrm{~s}$ and $5 p$ outer orbitals. The $4 \mathrm{f}$ inner shell transitions can generate different arrangements of new energy levels, improving the transfer and photogenerated lifetime of the carriers, and finally increasing the formation of highly reactive and oxidative radicals during the photocatalytic degradation [15]. The $\mathrm{Nd}-\mathrm{TiO}_{2}$ NPs showed intense emission of $\mathrm{Nd}^{3+}$ ions under excitation by laser radiation with $\lambda_{\mathrm{ex}}=350 \mathrm{~nm}$ (Figure 5).

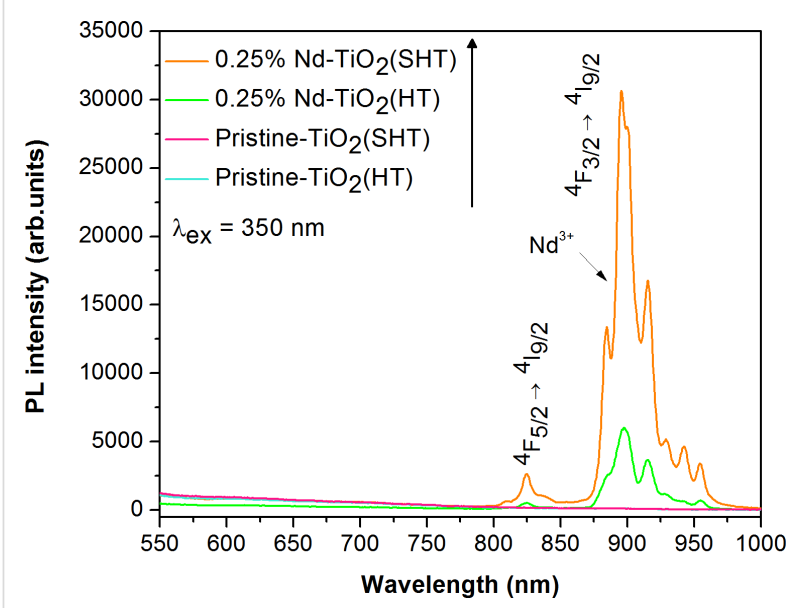

Figure 5: Photoluminescence spectra under laser light excitation $\left(\lambda_{\mathrm{ex}}=350 \mathrm{~nm}\right)$ of pristine $\mathrm{TiO}_{2}$ and $\mathrm{Nd}$-modified $\mathrm{TiO}_{2}$ prepared by sol-hydrothermal and hydrothermal methods.

The characteristic transition bands appeared in the near infrared range, with a maximum at around $900 \mathrm{~nm}\left({ }^{4} \mathrm{~F}_{3 / 2} \rightarrow{ }^{4} \mathrm{I}_{9 / 2}\right.$ transition) and a less intense peak at $850 \mathrm{~nm}\left({ }^{4} \mathrm{~F}_{5 / 2} \rightarrow{ }^{4} \mathrm{I}_{9 / 2}\right.$ transition $)$ [41]. The observed emission occurred because of a direct excitation of $\mathrm{Nd}^{3+}$ ions into the ${ }^{4} \mathrm{I}_{9 / 2} \rightarrow{ }^{4} \mathrm{D}_{1 / 2},{ }^{4} \mathrm{D}_{3 / 2},{ }^{4} \mathrm{D}_{5 / 2}$ absorption peak [42]. The sample prepared by the HT method showed lower emission intensity than the one prepared by the SHT method. This is a result of the differences in morphology between these two samples. According to Table 1, the $0.25 \%$ $\mathrm{Nd}-\mathrm{TiO}_{2}(\mathrm{HT})$ sample exhibited crystals that are roughly half the size, which increases the number of quenching processes of $\mathrm{Nd}^{3+}$ on the NP surfaces. The emission of NPs is more sensitive to interactions with the surrounding environment as a larger fraction of $\mathrm{Nd}^{3+}$ ions can be placed on the surface in comparison to bulk material. What is more, the surface of NPs usually exhibits more defects than, which also affects the luminescence [43]. The XPS results showed a lower concentration of $\mathrm{Nd}^{3+}$ ions in the sample prepared by the HT method, which may be another factor responsible for its reduced emission (see below in Table 2). Furthermore, the carbon content determined by XPS is the highest for the $0.25 \% \mathrm{Nd}^{-\mathrm{TiO}_{2}}(\mathrm{HT})$ sample. Hence, organic impurities might be considered as another factor quenching the luminescence of $\mathrm{Nd}^{3+}$ ions. The $\mathrm{Nd}^{3+}$-doped samples were also irradiated with 590, 750 and $808 \mathrm{~nm}$ laser light, however up-conversion luminescence was not detected. The $\mathrm{Nd}^{3+}$ ions have dense packaged energy levels, which limits the possible efficiency of up-conversion processes [20]. To obtain up-conversion of $\mathrm{Nd}^{3+}$ ions, good crystallization of the host material, revealing also low phonon energy is required [20]. The presence of $\mathrm{Nd}^{3+}$ ions in the $\mathrm{Nd}_{2} \mathrm{O}_{3}$ phase or in an environment that is highly defected and contaminated by organic impurities can also hinder the up-conversion process or even make it impossible to occur.

\section{Chemical composition}

To correlate the surface properties with the photoactivity of the obtained $\mathrm{Nd}-\mathrm{TiO}_{2}$, the surface layer of pristine $\mathrm{TiO}_{2}$ and Nd-modified $\mathrm{TiO}_{2}$ prepared by SHT and HT methods was examined by XPS. The existence of the titanium, oxygen and carbon has been proven in all samples and the corresponding amounts as well as the chemical character are presented in Figure 6 and in Table 2 and Table 3. The presence of neodymium was confirmed in both types of Nd-modified samples.

Elemental surface composition and chemical character of detected elements were identified by using high-resolution (HR) XPS of the Ti 2p, O 1s, C 1s and Nd 4d orbitals. The chemical character of elements is similar to that reported in our previously published paper [23].

The neodymium content (in wt \%) is consistent with the nominal amount of $\mathrm{Nd}$ introduced into the $\mathrm{Nd}-\mathrm{TiO}_{2}$ samples during preparation via the SHT method, while it is slightly lower in the sample obtained by the HT method (Table 2). Probably, the relatively large surface content of carbon species in the last sample results in a smaller $\mathrm{Nd}$ concentration (compare the $\mathrm{C} / \mathrm{Ti}$ and $\mathrm{Nd} / \mathrm{Ti}$ atomic concentration values in Table 2). The inspection of the XPS data in Table 3 reveals that the contribution of 


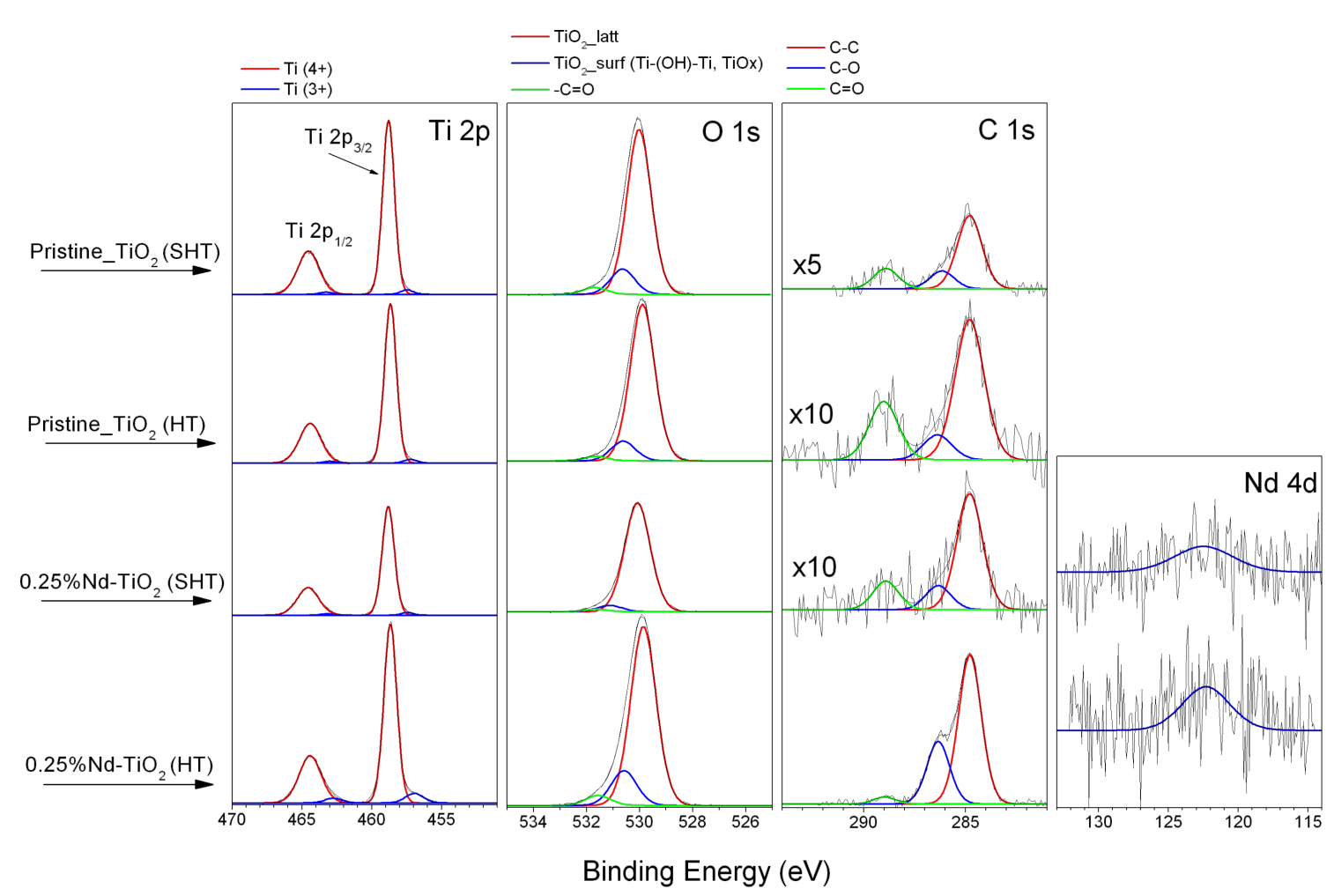

Figure 6: XPS spectra of pristine $\mathrm{TiO}_{2}$ and $\mathrm{Nd}$-modified $\mathrm{TiO}_{2}$.

Table 2: Chemical composition of pristine and $\mathrm{Nd}$-modified $\mathrm{TiO}_{2}$ photocatalysts based on XPS analysis.

\begin{tabular}{|c|c|c|c|c|c|c|}
\hline sample & Ti (wt \%) & $\mathrm{O}(\mathrm{wt} \%)$ & $\mathrm{C}($ wt $\%)$ & Nd (wt \%) & $\mathrm{C} / \mathrm{Ti}$ & $\mathrm{Nd} / \mathrm{Ti}$ \\
\hline pristine_ $\mathrm{TiO}_{2}(\mathrm{SHT})$ & 53.34 & 45.10 & 1.56 & 0 & 0.116 & 0 \\
\hline $0.25 \% \mathrm{Nd}-\mathrm{TiO}_{2}(\mathrm{SHT})$ & 54.01 & 44.84 & 0.89 & 0.24 & 0.065 & 0.0014 \\
\hline pristine_ $\mathrm{TiO}_{2}(\mathrm{HT})$ & 53.44 & 45.48 & 1.07 & 0 & 0.080 & 0 \\
\hline $0.25 \% \mathrm{Nd}-\mathrm{TiO}_{2}(\mathrm{HT})$ & 51.19 & 44.11 & 4.54 & 0.17 & 0.353 & 0.0012 \\
\hline
\end{tabular}

\begin{tabular}{|c|c|c|c|c|c|c|c|c|}
\hline \multirow{2}{*}{ sample } & \multicolumn{2}{|c|}{ Ti fraction (\%) } & \multicolumn{3}{|c|}{ O fraction (\%) } & \multicolumn{3}{|c|}{ C fraction (\%) } \\
\hline & $\operatorname{Ti}(4+)$ & $\mathrm{Ti}(3+)$ & $\mathrm{Ti}-\mathrm{O}_{\text {latt }}$ & $\mathrm{Ti}-\mathrm{O}_{\text {surf }}$ & $-\mathrm{C}=\mathrm{O}$ & $\mathrm{C}-\mathrm{C}$ & $\mathrm{C}-\mathrm{OH}$ & $-\mathrm{C}=\mathrm{O}$ \\
\hline pristine_ $\mathrm{TiO}_{2}(\mathrm{SHT})$ & 97.11 & 2.89 & 83.50 & 12.88 & 3.62 & 65.50 & 16.07 & 18.43 \\
\hline $0.25 \% \mathrm{Nd}-\mathrm{TiO}_{2}(\mathrm{SHT})$ & 97.48 & 2.52 & 92.59 & 5.40 & 2.01 & 68.80 & 14.25 & 16.95 \\
\hline pristine_ $\mathrm{TiO}_{2}(\mathrm{HT})$ & 97.31 & 2.69 & 86.58 & 10.96 & 2.46 & 62.62 & 11.21 & 26.17 \\
\hline $0.25 \% \mathrm{Nd}-\mathrm{TiO}_{2}(\mathrm{HT})$ & 92.74 & 7.26 & 79.83 & 15.63 & 4.54 & 68.13 & 28.66 & 3.21 \\
\hline
\end{tabular}

$\mathrm{Ti}-\mathrm{O}_{\text {surf }}(\mathrm{Ti}-(\mathrm{OH})-\mathrm{Ti}, \mathrm{TiO} x)$ and $\mathrm{C}-\mathrm{OH}$ fractions in the surface region of $0.25 \% \mathrm{Nd}-\mathrm{TiO}_{2}(\mathrm{HT})$ is larger than in other samples.

This clearly indicates the higher amount of hydroxy groups on the surface of the $\mathrm{Nd}-\mathrm{TiO}_{2}$ sample prepared via the HT method.
The presence of the $\mathrm{Ti}-\mathrm{O}_{\text {surf }}$ species can initiate the formation of $\mathrm{Ti}-\mathrm{O}-\mathrm{Nd}$ bonds. In addition, the $\mathrm{Ti}^{3+}$ fraction in the surface region of the $0.25 \% \mathrm{Nd}-\mathrm{TiO}_{2}(\mathrm{HT})$ sample is significantly larger than in the corresponding $0.25 \% \mathrm{Nd}-\mathrm{TiO}_{2}(\mathrm{SHT})$ sample (Table 3). The XPS data correspond well with the highest photocatalytic activity exhibited by the $0.25 \% \mathrm{Nd}-\mathrm{TiO}_{2}$ photocata- 
lyst prepared via HT method (described in detail in the next section).

\section{Photocatalytic properties}

The photocatalytic properties of pristine and Nd-modified $\mathrm{TiO}_{2}$ were investigated using the photocatalytic degradations of phenol in aqueous solution and of gaseous toluene. Kinetics and degradation rate of model pollutants are presented in Figure 7 and Table 4.

The photodegradation of phenol was performed in aqueous solution under UV-vis $(\lambda>350 \mathrm{~nm})$ and vis $(\lambda>420 \mathrm{~nm})$ light irradiation. The data showed that the photocatalytic activitiy of Nd-modified $\mathrm{TiO}_{2}$ NPs were lower than that of pristine $\mathrm{TiO}_{2}$ under UV-vis irradiation. The highest activity was observed for pristine $\mathrm{TiO}_{2}$ prepared via the HT method, with the phenol degradation rate reaching $1.59 \mu \mathrm{mol} \cdot \mathrm{dm}^{-1} \cdot \mathrm{min}^{-1}$. In the case of Nd-modified samples, the photocatalysts prepared via the HT method also showed higher activity (the degradation rate was equal to $1.22 \mu \mathrm{mol} \cdot \mathrm{dm}^{-1} \cdot \mathrm{min}^{-1}$ ). It should be pointed out that samples prepared by the HT process revealed the highest inhibition of recombination of the photogenerated charge carriers (see Figure 4). The observed decrease of photocatalytic activity of $\mathrm{Nd}$-modified $\mathrm{TiO}_{2}$ is due to the presence of $\mathrm{Nd}^{3+}$ ions on the surface of the $\mathrm{TiO}_{2}$ NPs, which lowered the excitation under UV irradiation. The UV irradiation does not yield sufficiently high energy of photons to penetrate deeper into the surface of the material [11]. This phenomenon can also be explained by the spectroscopic properties of rare earth ions. In our previous paper [23], it has been proven that $\mathrm{Nd}^{3+}$ ions are prone to crossrelaxation (energy migration between $\mathrm{Nd}^{3+}$ ions). Therefore, $\mathrm{Nd}^{3+}$ ions could absorb UV irradiation and emit energy in radiative transitions (luminescence). The photocatalytic properties of the as-prepared samples in the aqueous phase were also investigated under visible light irradiation (Figure 6b). The Nd-modified $\mathrm{TiO}_{2}$ has the ability to degrade effectively phenol under visible light, while pristine $\mathrm{TiO}_{2}$ shows only weak activity. The photocatalyst $0.25 \% \mathrm{Nd}-\mathrm{TiO}_{2}(\mathrm{HT})$ exhibited the highest photocatalytic activity with a phenol degradation rate of $0.62 \mu \mathrm{mol} \cdot \mathrm{dm}^{-1} \cdot \mathrm{min}^{-1}$. Moreover, the lower photocatalytic activity of $\mathrm{Nd}-\mathrm{TiO}_{2}$ sample prepared via the SHT method under UV-vis and vis irradiation $\left(0.99\right.$ and $0.31 \mu \mathrm{mol} \cdot \mathrm{dm}^{-1} \cdot \mathrm{min}^{-1}$, respectively), is the consequence of a small amount of surface adsorbed hydroxy groups. A similar decrease of photoactivity for RE-modified $\mathrm{TiO}_{2}$ was reported in our previous paper [24]. It was shown that photocatalysts prepared by the sol-gel method contain less $\mathrm{OH}$ groups than the powders obtained via the hydrothermal method, and the latter exhibited lower activity under UV-vis light irradiation. This behaviour was also observed by Tobaldi and co-workers [44]. They concluded that the overall photocatalytic activity is strongly influenced by surface
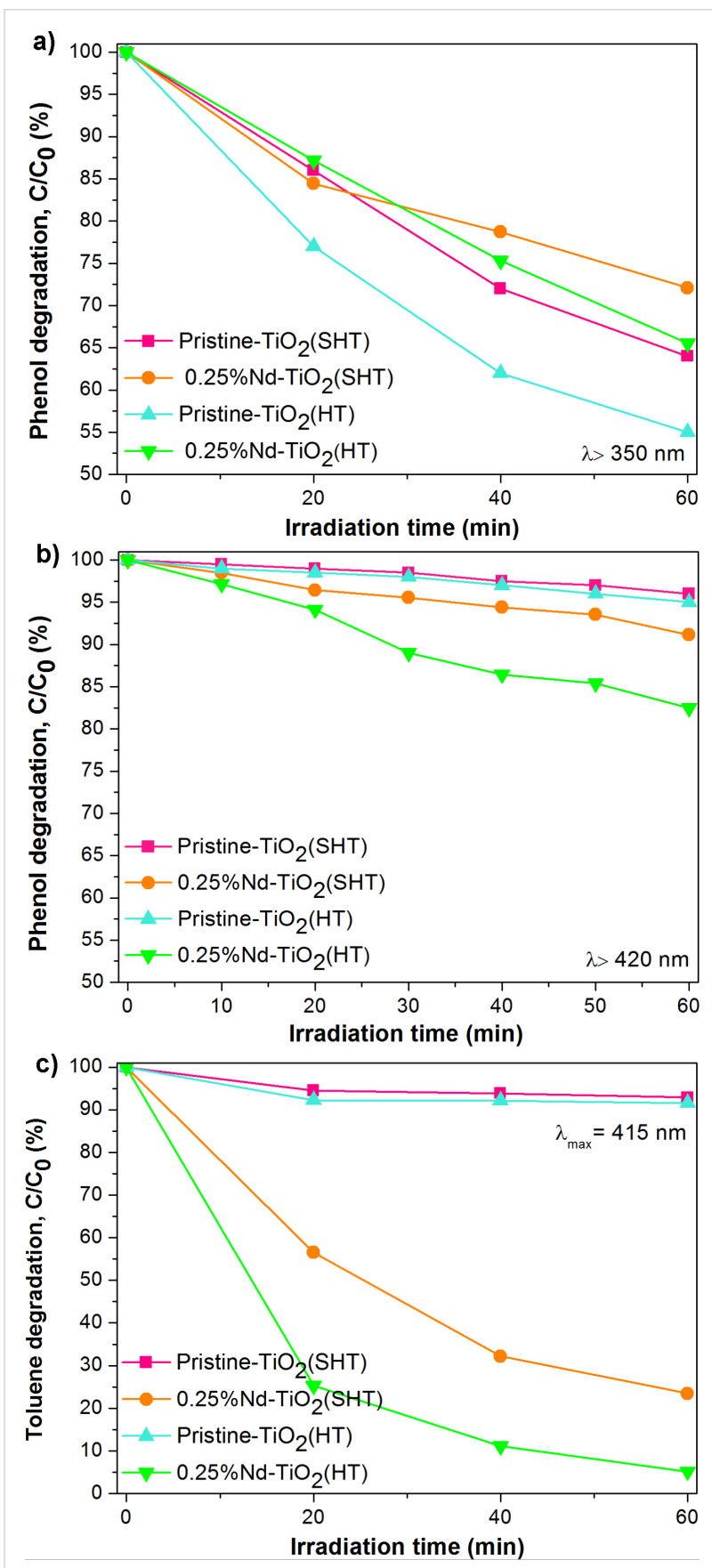

Figure 7: Photocatalytic activity of pristine and Nd-modified $\mathrm{TiO}_{2} \mathrm{NPs}$. Degradation of phenol in aqueous solution under (a) UV-vis and (b) vis irradiation, and degradation of gaseous toluene under (c) vis irradiation.

hydroxyl groups helping to generate reactive oxygen species, such as hydroxyl radicals.

The photocatalytic degradation of toluene was carried out under LED irradiation $\left(\lambda_{\max }=415 \mathrm{~nm}\right)$. A high photocatalytic activity was exhibited by all the neodymium-modified photocatalysts (Figure 6c). The rate of toluene degradation was 
Table 4: Photocatalytic activity under UV-vis and vis irradiation of pristine and Nd-modified $\mathrm{TiO}_{2}$ photocatalysts.

\begin{tabular}{|c|c|c|c|c|c|c|c|}
\hline \multirow[t]{2}{*}{ sample label } & \multirow{2}{*}{$\begin{array}{l}\text { toluene degradation } \\
\text { rate }\left(\mu \mathrm{mol} \cdot \mathrm{dm}^{-1} \cdot \mathrm{min}^{-1}\right) \\
\text { under vis } \\
\left(\lambda_{\max }=415 \mathrm{~nm}\right) \\
\text { irradiation }\end{array}$} & \multicolumn{2}{|c|}{$\begin{array}{l}\text { phenol degradation rate } \\
\left(\mu \mathrm{mol} \cdot \mathrm{dm}^{-1} \cdot \mathrm{min}^{-1}\right)\end{array}$} & \multicolumn{4}{|c|}{$\begin{array}{l}\text { phenol degradation rate }\left(\mu \mathrm{mol} \cdot \mathrm{dm}^{-1} \cdot \mathrm{min}^{-1}\right) \text { with } \\
\text { added scavenger under vis }(\lambda>420 \mathrm{~nm}) \text { irradiation }\end{array}$} \\
\hline & & $\begin{array}{l}\text { under UV-vis } \\
(\lambda>350 \mathrm{~nm}) \\
\text { irradiation }\end{array}$ & $\begin{array}{l}\text { under vis } \\
(\lambda>420 \mathrm{~nm}) \\
\text { irradiation }\end{array}$ & $\begin{array}{l}\text { silver } \\
\text { nitrate }\end{array}$ & $\begin{array}{l}\text { ammonium } \\
\text { oxalate }\end{array}$ & benzoquinone & tert-butanol \\
\hline pristine- $\mathrm{TiO}_{2}(\mathrm{SHT})$ & 0.25 & 1.28 & 0.14 & - & - & - & - \\
\hline $0.25 \% \mathrm{Nd}-\mathrm{TiO}_{2}(\mathrm{SHT})$ & 2.71 & 0.99 & 0.31 & 0.12 & 0.30 & 0.22 & 0.30 \\
\hline pristine- $\mathrm{TiO}_{2}(\mathrm{HT})$ & 0.30 & 1.59 & 0.18 & - & - & - & - \\
\hline $0.25 \% \mathrm{Nd}-\mathrm{TiO}_{2}(\mathrm{HT})$ & 3.36 & 1.22 & 0.62 & 0.15 & 0.58 & 0.21 & 0.57 \\
\hline
\end{tabular}

$3.36 \mu \mathrm{mol} \cdot \mathrm{dm}^{-1} \cdot \mathrm{min}^{-1}$ for HT-prepared $\mathrm{TiO}_{2}$ modified with $\mathrm{Nd}$, while the photodegradation efficiency decreased in SHTprepared $\mathrm{TiO}_{2}$ down to $2.71 \mu \mathrm{mol} \cdot \mathrm{dm}^{-1} \cdot \mathrm{min}^{-1}$. Pristine $\mathrm{TiO}_{2}$ exhibits only low activity (Figure 6c). As photolysis of toluene was not observed and the toluene concentration decreased in the dark experiment by approximately $6.5 \%$ for all samples, probably pollutant was adsorbed on the surface of $\mathrm{TiO}_{2}$ and on the walls of the reactor. A correlation between photocatalytic activity measured in both model reactions and the BET surface area was not observed. Based on XPS analysis, it can be seen that photocatalysts prepared via the HT method had a higher amount of hydroxy groups on the surface than those obtained by the SHT method. The hydroxy groups can act as adsorption centres on which the degradation of pollutants takes place [45]. Moreover, a high amount of oxygen vacancies and defects was found on the surface of the $0.25 \% \mathrm{Nd}-\mathrm{TiO}_{2}(\mathrm{HT})$ sample. As previously mentioned, the presence of oxygen deficient centres on the surface and surface defects such as $\mathrm{Ti}^{3+}$ can reduce the rate of electron-hole pair recombination [45-47]. Further, the light adsorption ability could be strongly related to the band-gap structure, which is affected by defects. With a reduced band gap or addition of sub-bands, $\mathrm{TiO}_{2}$ can respond to visible light, in- creasing its light absorption efficiency [48]. A schematic illustration showing impact of the preparation methods on the surface properties and the charge carrier recombination processes is presented in Figure 8.

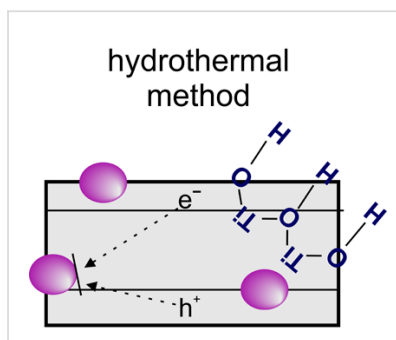

less $\mathrm{e}^{-} / \mathrm{h}^{+}$recombination sol-hydrothermal method

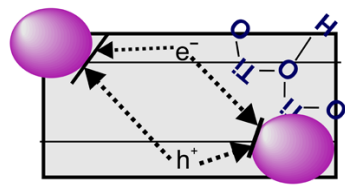

more $\mathrm{e}^{-} / \mathrm{h}^{+}$recombination

$\mathrm{Nd}_{2} \mathrm{O}_{3}$
Figure 8: Schematic illustration showing the impact of preparation methods on the surface properties and the charge carrier recombination processes.

The results of the photodegradation significant differences between aqueous solution and gas phase. The quantum yield of
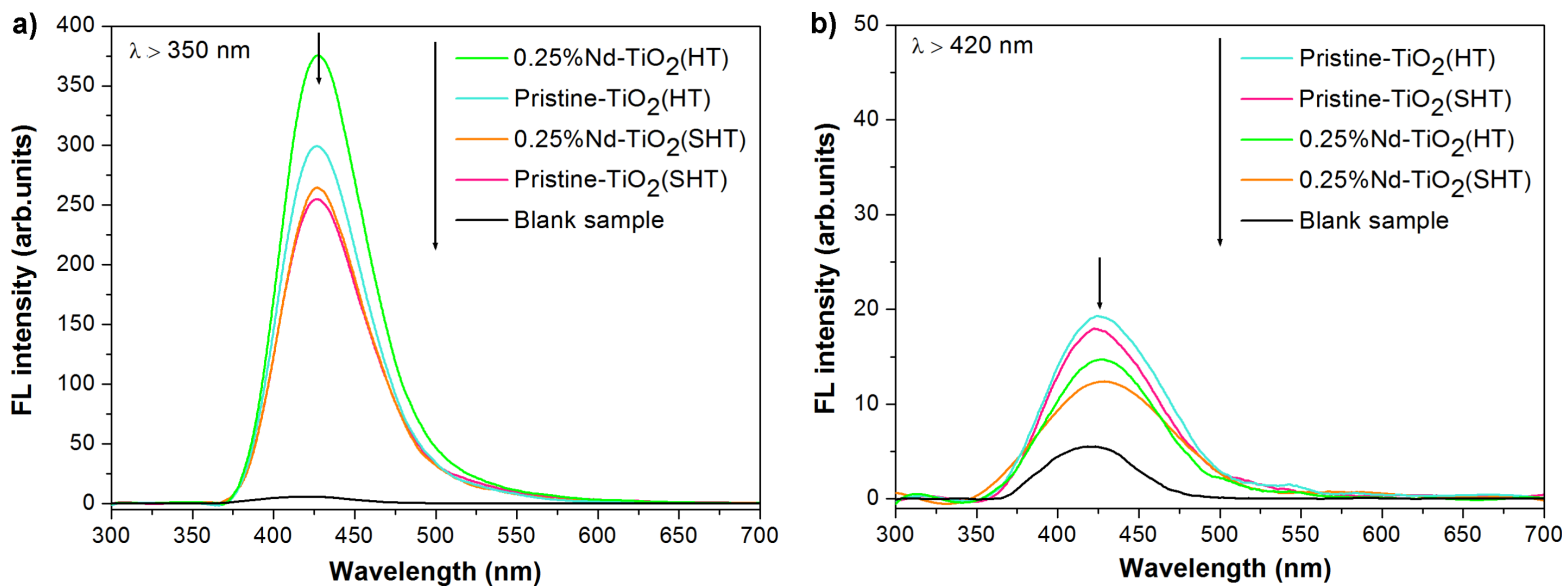

Figure 9: Fluorescence spectral changes in a solution of terephthalic acid under (a) UV-vis $(\lambda>350 \mathrm{~nm})$ and (b) vis $(\lambda>420 \mathrm{~nm})$ light irradiation. 
the reaction in the gas phase is much higher than that one in aqueous solution due to lower light scattering. Also, a lower irradiation intensity is required to perform the photocatalytic reaction in the gas phase $[8,49]$.

\section{Degradation mechanism}

Based on the obtained results, it can be stated that the Nd-modified $\mathrm{TiO}_{2}$ could be effectively excited by irradiation with visible light. To explore which active species are responsible for the degradation of phenol under vis irradiation, hydroxyl radical generation tests with terephthalic acid (TPA) were performed. Figure 9 shows the fluorescence of 2-hydroxyterephthalic acid after $60 \mathrm{~min}$ in the presence of pristine and Nd-modified $\mathrm{TiO}_{2}$ under UV-vis and vis light. The increase in intensity of the fluorescent peak indicates the formation of ${ }^{\circ} \mathrm{OH}$ radicals produced in the aqueous solution.

As shown in Figure 9a, the presence of $\mathrm{Nd}^{3+}$ increases the intensity of the peaks. This indicates that $\mathrm{Nd}^{3+}$ effectively leads to an increase in the production of hydroxyl radicals on the surface of the photocatalysts under UV-vis light irradiation. Moreover, the obtained results showed that the intensity of the FL spectra increases for the HT series of photocatalysts. The obtained results correlate with photocatalytic activity under UV-vis light. It should be mentioned that the number of hydroxyl radicals is increased under the influence of UV-vis irradiation in the presence of $\mathrm{Nd}$-modified $\mathrm{TiO}_{2}$ compared to pristine $\mathrm{TiO}_{2}$. However, the observed efficiency of phenol degradation in presence of $\mathrm{Nd}-\mathrm{TiO}_{2}$ was much lower. The difference is caused by the different reaction paths of phenol photodegradation and formation of 2-hydroxyterephthalic acid from TPA through generated ${ }^{\circ} \mathrm{OH}$ radicals. Based on the available literature, the TPA formation depends only on the amount of ${ }^{\circ} \mathrm{OH}$ radicals generated at the surface of the excited semiconductor. The phenol degradation can result from: (i) the reaction of ${ }^{\circ} \mathrm{OH}$ with phenol, (ii) the reaction of phenol with photogenerated holes in $\mathrm{TiO}_{2}$, and (iii) by direct oxidation of phenol through oxygen dissolved in water [50]. When the TPA test was carried out under vis irradiation (Figure 9b), the FL intensity was close to zero for all samples. Based on the presented results it can be stated that the modification of $\mathrm{TiO}_{2}$ with $\mathrm{Nd}$ ions does not increase the production of hydroxyl radicals under visible light irradiation. According to our previous paper, the photodegradation of phenol under vis light irradiation occurs through the other forms of reactive oxygen species such as $\mathrm{O}_{2}{ }^{--}, \mathrm{HO}_{2}{ }^{\bullet}$ and $\mathrm{H}_{2} \mathrm{O}_{2}[8,23]$.

In order to better understand which reactive oxygen species may be important in the photocatalytic process, the photocatalytic activity tests in aqueous solution have been carried out in the presence of $\mathrm{Nd}-\mathrm{TiO}_{2}$ and different scavengers (Figure 10).

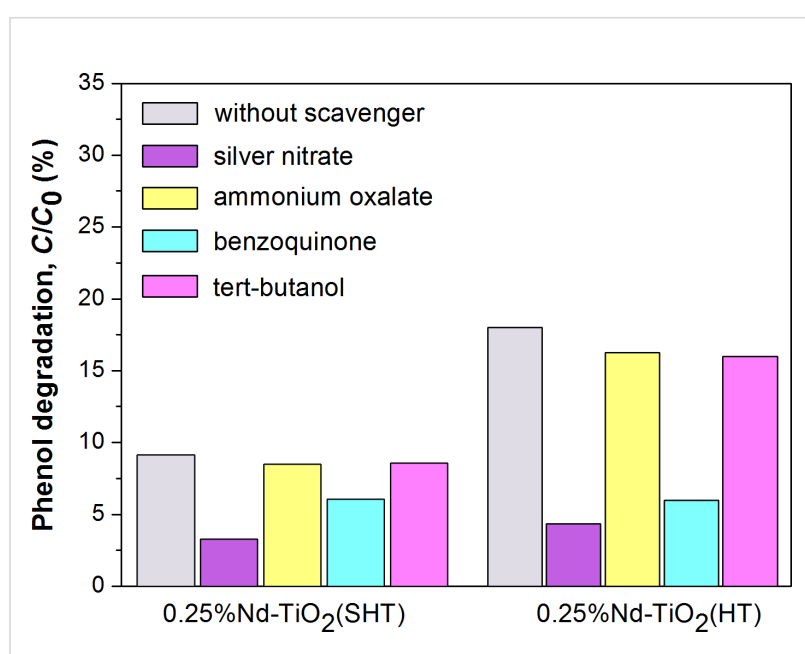

Figure 10: Photocatalytic decomposition of phenol in the presence of Nd-modified $\mathrm{TiO}_{2}$ and scavengers after $60 \mathrm{~min}$ of visible $(\lambda>420 \mathrm{~nm})$ irradiation.

Silver nitrate was used as electron scavenger, ammonium oxalate as hole scavenger, benzoquinone for $\mathrm{O}_{2}{ }^{--}$and tert-butanol for ${ }^{\circ} \mathrm{OH}$ radicals. After $60 \mathrm{~min}$ of visible light irradiation in the presence of SHT photocatalyst, the degradation rate declined from 0.31 to $0.30 \mu \mathrm{mol} \cdot \mathrm{dm}^{-1} \cdot \mathrm{min}^{-1}$ due to addition of ammonium oxalate and tert-butanol (Table 4). While, after the addition of silver nitrate and benzoquinone, the degradation rate decreased from 0.31 to 0.12 and $0.22 \mu \mathrm{mol} \cdot \mathrm{dm}^{-1} \cdot \mathrm{min}^{-1}$, respectively, suggesting that photogenerated electrons and superoxide radicals are the main active species responsible for the degradation of the model pollutants. In the presence of HT photocatalyst with scavengers similar phenomena were observed. The photocatalytic system with added ammonium oxalate and tert-butanol showed congruous degradation rates $(0.58$ and $0.57 \mu \mathrm{mol} \cdot \mathrm{dm}^{-1} \cdot \mathrm{min}^{-1}$, respectively) compared to the system without scavengers $\left(0.62 \mu \mathrm{mol} \cdot \mathrm{dm}^{-1} \cdot \mathrm{min}^{-1}\right)$, suggesting a limited role played by holes in the photocatalytic process. The addition of silver nitrate and benzoquinone significantly reduced the phenol degradation rate (from 0.62 to 0.15 and $0.21 \mu \mathrm{mol} \cdot \mathrm{dm}^{-1} \cdot \mathrm{min}^{-1}$, respectively), indicating that superoxide radical is the major active species in this system. These experiments also showed that for the photodegradation of phenol with the photocatalyst prepared via HT method, a larger suppression was noted upon the addition of benzoquinone, compared to the photocatalyst prepared via SHT method. This suggests that $0.25 \% \mathrm{Nd}-\mathrm{TiO} 2(\mathrm{HT})$ generates a bigger amount of $\mathrm{O}_{2}{ }^{\cdot-}$. The reaction of electrons in the conduction band of $\mathrm{TiO}_{2}$ is probably responsible for the formation of $\mathrm{O}_{2}{ }^{--}$. Electrons from the conduction band of $\mathrm{TiO}_{2}$, generated by the excitation of the $\mathrm{Nd}^{3+}$, migrate to the surface of the semiconductor where they are involved in the formation of $\mathrm{O}_{2}{ }^{--}$and then $\mathrm{H}_{2} \mathrm{O}_{2}$ and $\mathrm{HO}_{2}{ }^{\circ}$, as presented in the following reactions [8]: 
Nd-modified $\mathrm{TiO}_{2}+h v \longrightarrow e^{-}$

$$
\begin{gathered}
e^{-}+\mathrm{O}_{2} \longrightarrow \mathrm{O}_{2}^{\cdot-} \\
e^{-}+\mathrm{O}_{2}^{\cdot-}+2 \mathrm{H}^{+} \longrightarrow \mathrm{H}_{2} \mathrm{O}_{2} \\
\mathrm{O}_{2}^{\cdot-}+\mathrm{H}^{+} \longrightarrow \mathrm{HO}_{2}^{\cdot} \\
\mathrm{O}_{2}{ }^{\cdot-}, \mathrm{H}_{2} \mathrm{O}_{2}, \mathrm{HO}_{2}{ }^{\cdot}+\text { phenol/toluene } \\
\longrightarrow \text { byproducts }+\mathrm{CO}_{2}+\mathrm{H}_{2} \mathrm{O} .
\end{gathered}
$$

The proposed photocatalytic mechanism under visible light can be explained by the energy diagram shown in Figure 11.

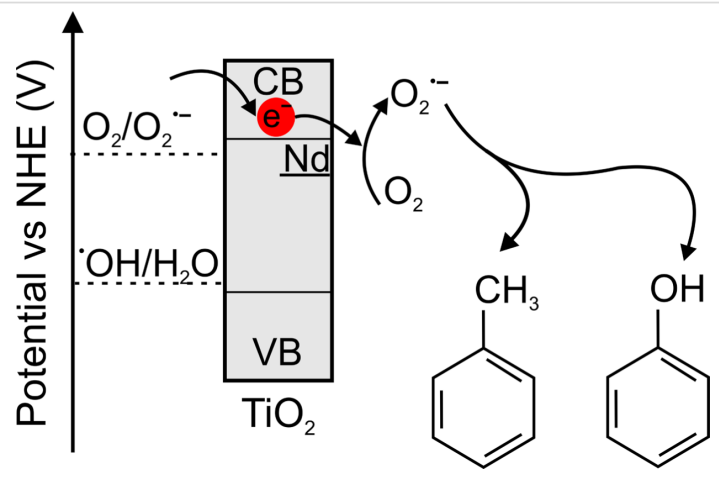

Figure 11: Proposed photocatalytic mechanism of $\mathrm{Nd}$-modified $\mathrm{TiO}_{2}$ under visible light.

\section{Conclusion}

We have observed how the spectroscopic properties of $\mathrm{Nd}^{3+}$ ions on the surface of $\mathrm{TiO}_{2} \mathrm{NPs}$ can be conveniently exploited for a variety of environmental purification processes. We presented the experimental studies concerning the effect of synthesis methods on the photocatalytic activity of Nd-modified $\mathrm{TiO}_{2}$. Nanocrystalline anatase-phase $\mathrm{TiO}_{2} \mathrm{NPs}$ were successfully prepared via hydrothermal and sol-hydrothermal methods. Both Nd-modified samples can achieve the photocatalytic degradation of phenol and toluene under visible light, and $\mathrm{Nd}-\mathrm{TiO}_{2}$ has a higher activity than pristine $\mathrm{TiO}_{2}$ (2.25- and 6.3-times higher activity for $0.25 \% \mathrm{Nd}-\mathrm{TiO}_{2}(\mathrm{SHT})$, and 3.6- and 7.1times higher activity for $0.25 \% \mathrm{Nd}-\mathrm{TiO}_{2}(\mathrm{HT})$, respectively). This is mainly due to the increase of the BET surface area, the decrease of the anatase crystallite size and the prevention of recombination of charge carriers. The surface properties of the $\mathrm{Nd}-\mathrm{TiO}_{2} \mathrm{NPs}$ obtained via hydrothermal method yield a significantly higher photocatalytic activity compared to $\mathrm{Nd}-\mathrm{TiO}_{2} \mathrm{NPs}$ prepared via sol-hydrothermal process. The photocatalyst prepared via HT method has three times more hydroxy groups on its surface layer and a two times higher amount of surface defects than the powder obtained by SHT method. According to the photocatalytic degradation experiments, the Nd-modified $\mathrm{TiO}_{2}$ photocatalyst preparated via HT method can be effectively used for air purification using LED irradiation (the degra- dation rate of toluene reached $3.36 \mu \mathrm{mol} \cdot \mathrm{dm}^{-1} \cdot \mathrm{min}^{-1}$ ). Furthermore, photocatalytic activity test in the presence of ${\mathrm{Nd}-\mathrm{TiO}_{2}}_{2}$ and scavengers confirm that superoxide radicals were responsible for the visible-light degradation of the model pollutant in aqueous solution.

\section{Experimental Materials}

Titanium(IV) butoxide (97\%, TBOT) and $\mathrm{Nd}\left(\mathrm{NO}_{3}\right)_{3} \cdot 6 \mathrm{H}_{2} \mathrm{O}$ (99.99\%) were purchased from Sigma-Aldrich, Poland. Nitric acid (65\%) and hydrochloric acid (31-38\%) were purchased from STANLAB, Poland. Ethanol, phenol and terephthalic acid were purchased from POCh S.A, Poland. P25 from Evonik, Germany was used as a standard and for comparison of the photocatalytic activity. Deionised water $(0.05 \mu \mathrm{S})$ was used for all reactions and treatment processes. All the chemicals were used as received without further purification.

\section{Preparation of $\mathrm{Nd}-\mathrm{TiO}_{2}$}

$\mathrm{Nd}-\mathrm{TiO}_{2} \mathrm{NPs}$ were synthesized by two methods, i.e., hydrothermal (HT) and sol-hydrothermal (SHT).

\section{HT method}

In a typical procedure, $15 \mathrm{~mL}$ of TBOT was dissolved in $80 \mathrm{~mL}$ of ethanol. Then, $40 \mathrm{~mL}$ water ( $\mathrm{pH} 3$ adjusted with $\mathrm{HCl}$ ) was added dropwise. Next, a certain amount of solid $\mathrm{Nd}\left(\mathrm{NO}_{3}\right)_{3} \cdot 6 \mathrm{H}_{2} \mathrm{O}$ was added. The mixture was stirred for $30 \mathrm{~min}$ at room temperature and treated at $180{ }^{\circ} \mathrm{C}$ for $6 \mathrm{~h}$ in a $200 \mathrm{~mL}$ autoclave.

\section{SHT method}

In the first step, $24 \mathrm{~mL}$ TBOT was dissolved in $48 \mathrm{~mL}$ ethanol (solution A), and stirred for $15 \mathrm{~min}$. Then, to $48 \mathrm{~mL}$ ethanol, $20 \mathrm{~mL}$ water, and $1.90 \mathrm{~mL} \mathrm{HNO}_{3}$ was added a certain amount of solid $\mathrm{Nd}\left(\mathrm{NO}_{3}\right)_{3} \cdot 6 \mathrm{H}_{2} \mathrm{O}$ (solution $\mathrm{B}$ ). In the next step, solution $\mathrm{B}$ was added to solution A dropwise and stirred for $30 \mathrm{~min}$ at room temperature. The obtained sol was treated at $160{ }^{\circ} \mathrm{C}$ for $3 \mathrm{~h}$ in a $200 \mathrm{~mL}$ autoclave.

The samples obtained from both methods were separated by centrifugation, washed three times with deionised water and ethanol, and dried at $35^{\circ} \mathrm{C}$ for $16 \mathrm{~h}$ and ground. Crystallization of titania was performed at a temperature of $450^{\circ} \mathrm{C}$ for $2 \mathrm{~h}$ in a muffle furnace under air atmosphere with a heating rate of $2{ }^{\circ} \mathrm{C} / \mathrm{min}$ followed by grinding to obtain the $\mathrm{Nd}-\mathrm{TiO}_{2}$ powders. For comparison, $\mathrm{TiO}_{2}$ without $\mathrm{Nd}$ was prepared likewise. A description of the prepared photocatalysts is shown in Table 1.

\section{Characterization of $\mathrm{Nd}-\mathrm{TiO}_{2}$}

$\mathrm{X}$-ray diffraction (XRD) was used to determine and verify the crystalline structure of the obtained photocatalysts. XRD 
patterns were recorded on a Rigaku diffractometer (RINT Ultima+) equipped with a graphite monochromator using $\mathrm{Cu}$ $\mathrm{K} \alpha$ radiation ( $40 \mathrm{kV}$ tube voltage and $20 \mathrm{~mA}$ tube current). Measurements were performed in a $2 \theta$ range of $5-90^{\circ}$. Based on the results obtained, the particle sizes of photocatalysts and XRD data were calculated using the Scherrer equation.

Nitrogen adsorption-desorption isotherms were measured at $-196{ }^{\circ} \mathrm{C}$ (liquid nitrogen temperature) using a Micromeritics Gemini V (model 2365). The surface area was determined according to the standard Brunauer-Emmet-Teller (BET) method. All samples were degassed at $200{ }^{\circ} \mathrm{C}$ prior to nitrogen adsorption measurements.

The morphology of obtained $\mathrm{Nd}-\mathrm{TiO}_{2}$ was determined using scanning electron microscopy (SEM, FEI Quanta 250 FEG).

UV-vis diffuse reflectance spectra of the synthesized materials were recorded in the range of $200-850 \mathrm{~nm}$ with a scanning speed of $200 \mathrm{~nm} / \mathrm{min}$ at room temperature using a Shimadzu UV-vis spectrophotometer (UV 2600) equipped with an integrating sphere. $\mathrm{BaSO}_{4}$ was used as the reference.

Photoluminescence (PL) properties in the range of 300-700 nm were measured on a Perkin Elmer limited LS50B spectrophotometer equipped with a xenon discharge lamp as an excitation source and an R928 photomultiplier as a detector. The spectra were recorded with an excitation wavelength of $315 \mathrm{~nm}$ directed on the sample surface at an angle of $90^{\circ}$. PL spectra in the range covering $\mathrm{Nd}^{3+}$ emission (550-1000 nm) were measured with a Princeton Instrument PIXIS:256E digital CCD camera, equipped with a SP-2156 Imaging Spectrograph and an Opolette 355LD UVDM tunable laser as the excitation source.

X-ray photoelectron spectroscopy (XPS) measurements were used for chemical characterization of the $\mathrm{Nd}-\mathrm{TiO}_{2}$ composites surface. The high-resolution (HR) XPS spectra were recorded on PHI 5000 VersaProbe (ULVAC-PHI) spectrometer with monochromatic Al $\mathrm{K} \alpha$ radiation $(h v=1486.6 \mathrm{eV})$. The binding energy (BE) scales of all detected HR spectra were calibrated by centering the aliphatic carbon peak $(\mathrm{C}-\mathrm{C})$ at $284.8 \mathrm{eV}$.

\section{Measurement of photocatalytic activity}

The photocatalytic activity of the obtained $\mathrm{Nd}-\mathrm{TiO}_{2}$ samples was studied in two model processes, namely decomposition of phenol in aqueous solution and degradation of gaseous toluene. In addition, to determine which reactive oxygen species participate in the degradation mechanism, a hydroxyl radical test using terephthalic acid and a reactive oxygen species formation test using benzoquinone, silver nitrate, ammonium oxalate and tertbutanol as scavengers were carried out.
Measurements of phenol decomposition and generation of ${ }^{\bullet} \mathrm{OH}$ radicals were carried out for two irradiation ranges, UV-vis $(\lambda>350 \mathrm{~nm})$ and vis $(\lambda>420 \mathrm{~nm})$, while scavenger test was carried under vis $(\lambda>420 \mathrm{~nm})$ light irradiation, using a $1000 \mathrm{~W}$ Xenon lamp (Oriel 66021). The optical path included a water filter to cut off IR irradiation. For the test of UV-vis and vis light-induced activity the light beam passed through GG350 or GG420 filters to cut-off wavelengths shorter than 350 or $420 \mathrm{~nm}$, respectively. The experimental procedure was as follows: $\mathrm{Nd}-\mathrm{TiO}_{2}$ powder $(125 \mathrm{mg}$ ) was suspended in aqueous solutions of phenol $(0.21 \mathrm{mM})$ or terephthalic acid $(0.5 \mathrm{mM})$ or in an aqueous solution of scavenger and phenol in a quartz photoreactor (working volume of about $25 \mathrm{~mL}$ ). After $30 \mathrm{~min}$ of mixing $(550 \mathrm{rpm})$ and aeration $\left(5 \mathrm{dm}^{3} / \mathrm{h}\right)$ in the dark, the suspension was irradiated with a cut-off spectrum of light. The temperature of the suspension during photoirradiation was maintained at $10{ }^{\circ} \mathrm{C}$ using a thermostatically controlled water bath (to avoid the stripping process). Samples of $0.5 \mathrm{~mL}$ reaction mixture were collected after regular time periods during irradiation and filtered through syringe filters (diameter $0.2 \mu \mathrm{m}$ ) to remove the suspended photocatalyst particles. Kinetics of phenol degradation were determined by high-performance liquid chromatography (HPLC, Shimadzu). The HPLC system was equipped with a Kinetex C18 column $(150 \mathrm{~mm} \times 3 \mathrm{~mm}$; particle size of $2.6 \mu \mathrm{m}$; pore diameter $100 \AA)$ and the SPDM20A diode array detector $(\lambda=205 \mathrm{~nm})$. The flow rate was maintained at $0.4 \mathrm{~mL} / \mathrm{min}$ with a mobile phase composed of acetonitrile and water $(7.5 / 92.5 \mathrm{v} / \mathrm{v})$. The injection volume was $30 \mu \mathrm{L}$. For fluorescnece measurements, $2 \mathrm{~mL}$ of the reaction mixture of terephthalic acid were collected after 60 min irradiation and filtered through syringe filters (diameter $0.2 \mu \mathrm{m}$ ) to remove the suspended photocatalyst particles. Fluorescence spectra were measured at room temperature using a Perkin Elmer limited LS50B spectrophotometer equipped with a xenon discharge lamp as an excitation source and an R928 photomultiplier as a detector. The obtained solution was measured with an excitation wavelength of $315 \mathrm{~nm}$.

Decomposition of toluene in the gas phase was carried out in a flat stainless steel reactor with the working volume of about $35 \mathrm{~mL}$ equipped with a quartz window, two valves and a septum. An array of five LEDs $\left(\lambda_{\max }=415 \mathrm{~nm}\right)$ was used as an irradiation source. A glass plate covered by Nd-modified $\mathrm{TiO}_{2}$ was placed at the bottom side of the reactor followed by closing the reactor with a quartz window. Subsequently, the gaseous mixture was passed through the reaction chamber for $1 \mathrm{~min}$. After closing the valves, the reactor was kept in dark for $30 \mathrm{~min}$ in order to achieve adsorption equilibrium. A reference of $200 \mu \mathrm{L}$ sample was taken just before starting irradiation and further samples were collected after regular time periods during irradiation. The analysis of toluene concentration in the gas 
phase was performed using a gas chromatograph (Trace 1300, Thermo Scientific) equipped with a flame ionization detector (FID) and Elite-5 capillary column.

\section{Acknowledgements}

This research was financially supported by Polish National Science Centre (grant No. NCN 2015/17/D/ST5/01331 and No. NCN 2017/24/T/ST5/00221) and supported by the Foundation for Polish Science (FNP).

\section{ORCID ${ }^{\circledR}$ iDs}

Patrycja Parnicka - https://orcid.org/0000-0002-2953-2663 Paweł Mazierski - https://orcid.org/0000-0002-8674-0151 Tomasz Grzyb - https://orcid.org/0000-0002-2947-6366 Ewa Kowalska - https://orcid.org/0000-0003-0955-9268 Adriana Zaleska-Medynska - https://orcid.org/0000-0003-3817-296X Joanna Nadolna - https://orcid.org/0000-0001-7933-6663

\section{References}

1. Kowalska, E.; Janczarek, M.; Rosa, L.; Juodkazis, S.; Ohtani, B. Catal. Today 2014, 230, 131-137. doi:10.1016/j.cattod.2013.11.021

2. Scuderi, V.; Zimbone, M.; Miritello, M.; Nicotra, G.; Impellizzeri, G.; Privitera, V. Beilstein J. Nanotechnol. 2017, 8, 190-195. doi:10.3762/bjnano.8.20

3. Klein, M.; Nadolna, J.; Gołabiewska, A.; Mazierski, P.; Klimczuk, T.; Remita, H.; Zaleska-Medynska, A. Appl. Surf. Sci. 2016, 378, 37-48. doi:10.1016/j.apsusc.2016.03.191

4. Leong, K. H.; Chu, H. Y.; Ibrahim, S.; Saravanan, P. Beilstein J. Nanotechnol. 2015, 6, 428-437. doi:10.3762/bjnano.6.43

5. Lu, D.; Yang, M.; Fang, P.; Li, C.; Jiang, L. Appl. Surf. Sci. 2017, 399, 167-184. doi:10.1016/j.apsusc.2016.12.077

6. Fujishima, A.; Honda, K. Nature 1972, 238, 37-38. doi:10.1038/238037a0

7. Zaleska, A. Recent Pat. Eng. 2008, 2, 157-164. doi:10.2174/187221208786306289

8. Mazierski, P.; Lisowski, W.; Grzyb, T.; Winiarski, M. J.; Klimczuk, T.; Mikołajczyk, A.; Flisikowski, J.; Hirsch, A.; Kołakowska, A.; Puzyn, T.; Zaleska-Medynska, A.; Nadolna, J. Appl. Catal., B: Environ. 2017, 205, 376-385. doi:10.1016/j.apcatb.2016.12.044

9. Mazierski, P.; Nadolna, J.; Nowaczyk, G.; Lisowski, W.; Winiarski, M. J.; Klimczuk, T.; Kobylański, M. P.; Jurga, S.; Zaleska-Medynska, A. J. Phys. Chem. C 2017, 121, 17215-17225. doi:10.1021/acs.jpcc.7b03895

10. Reszczynska, J.; Esteban, D. A.; Gazda, M.; Zaleska, A. Physicochem. Probl. Miner. Process. 2014, 50, 515-524. doi:10.5277/ppmp140208

11. Reszczyńska, J.; Grzyb, T.; Sobczak, J. W.; Lisowski, W.; Gazda, M.; Ohtani, B.; Zaleska, A. Appl. Surf. Sci. 2014, 307, 333-345. doi:10.1016/j.apsusc.2014.03.199

12. Reszczynska, J.; Iwulska, A.; Sliwinski, G.; Zaleska, A Physicochem. Probl. Miner. Process. 2012, 48, 201-208.

13. Dominguez, R. D.; Alarcón-Flores, G.; Aguilar-Frutis, M.; Sánchez-Alarcón, R. I.; Falcony, C.; Dorantes-Rosales, H. J.; González-Velázquez, J. L.; Rivas-López, D. I. J. Alloys Compd. 2016, 687, 121-129. doi:10.1016/j.jallcom.2016.06.083
14. Reszczyńska, J.; Grzyb, T.; Sobczak, J. W.; Lisowski, W.; Gazda, M.; Ohtani, B.; Zaleska, A. Appl. Catal., B: Environ. 2015, 163, 40-49. doi:10.1016/j.apcatb.2014.07.010

15. Trujillo-Navarrete, B.; Haro-Vázquez, M. d. P.; Félix-Navarro, R. M.; Paraguay-Delgado, F.; Alvarez-Huerta, H.; Pérez-Sicairos, S.; Reynoso-Soto, E. A. J. Rare Earths 2017, 35, 259-270. doi:10.1016/S1002-0721(17)60909-8

16. Grzyb, T.; Tymiński, A. J. Alloys Compd. 2016, 660, 235-243. doi:10.1016/j.jallcom.2015.11.122

17. Tymiński, A.; Grzyb, T. J. Lumin. 2017, 181, 411-420. doi:10.1016/j.jlumin.2016.09.028

18. Grzyb, T.; Gruszeczka, A.; Lis, S. J. Lumin. 2016, 175, 21-27. doi:10.1016/j.jlumin.2016.02.021

19. Dias, J. D. M.; Melo, G. H. A.; Lodi, T. A.; Carvalho, J. O.; Façanha Filho, P. F.; Barboza, M. J.; Steimacher, A.; Pedrochi, F. J. Rare Earths 2016, 34, 521-528. doi:10.1016/S1002-0721(16)60057-1

20. Ramakrishna, P. V.; Pammi, S. V. N.; Samatha, K. Solid State Commun. 2013, 155, 21-24. doi:10.1016/j.ssc.2012.10.043

21. Castañeda-Contreras, J.; Marañón-Ruiz, V. F.; Chiu-Zárate, R.; Pérez-Ladrón de Guevara, H.; Rodriguez, R.; Michel-Uribe, C. Mater. Res. Bull. 2012, 47, 290-295. doi:10.1016/j.materresbull.2011.11.021

22. Wang, J.; Xie, Y.; Zhang, Z.; Li, J.; Chen, X.; Zhang, L.; Xu, R.; Zhang, X. Sol. Energy Mater. Sol. Cells 2009, 93, 355-361. doi:10.1016/j.solmat.2008.11.017

23. Parnicka, P.; Mazierski, P.; Grzyb, T.; Wei, Z.; Kowalska, E.; Ohtani, B.; Klimczuk, T.; Nadolna, J. J. Catal. 2017, 353, 211-222. doi:10.1016/j.jcat.2017.07.017

24. Reszczyńska, J.; Grzyb, T.; Wei, Z.; Klein, M.; Kowalska, E.; Ohtani, B.; Zaleska-Medynska, A. Appl. Catal., B: Environ. 2016, 181, 825-837. doi:10.1016/j.apcatb.2015.09.001

25. Sun, D.; Wang, K.; Xu, Z.; Li, R. J. Rare Earths 2015, 33, 491-497. doi:10.1016/S1002-0721(14)60446-4

26. Qin, Y.; Hu, Z.; Lim, B. H.; Chang, W. S.; Chong, K. K.; Zhang, P.; Zhang, H. J. Alloys Compd. 2016, 686, 803-809. doi:10.1016/j.jallcom.2016.06.179

27. Liu, Y.; Fang, P.; Cheng, Y.; Gao, Y.; Chen, F.; Liu, Z.; Dai, Y. Chem. Eng. J. 2013, 219, 478-485. doi:10.1016/j.cej.2012.12.098

28. Zhang, H.; Sheng, Y.; Song, Y.; Li, H.; Huang, J.; Zheng, K.; Huo, Q.; Xu, X.; Zou, H. Powder Technol. 2013, 239, 403-408. doi:10.1016/j.powtec.2013.02.010

29. Cacciotti, I.; Bianco, A.; Pezzotti, G.; Gusmano, G. Chem. Eng. J. 2011, 166, 751-764. doi:10.1016/j.cej.2010.07.008

30. Yuan, M.; Zhang, J.; Yan, S.; Luo, G.; Xu, Q.; Wang, X.; Li, C. J. Alloys Compd. 2011, 509, 6227-6235. doi:10.1016/j.jallcom.2011.03.010

31. Thomas, J.; Radhika, S.; Yoon, M. J. Mol. Catal. A: Chem. 2016, 411, 146-156. doi:10.1016/j.molcata.2015.10.021

32. Luo, X.; Zhu, S.; Wang, J.; Wang, C.; Wu, M. Int. J. Environ. Res. Public Health 2017, 14, 1471. doi:10.3390/ijerph14121471

33. Qu, X.; Yan, X.; Hou, Y.; Wang, P.; Song, H.; Du, F. J. Sol-Gel Sci. Technol. 2015, 76, 699-707. doi:10.1007/s10971-015-3823-0

34. Wojcieszak, D.; Mazur, M.; Kurnatowska, M.; Kaczmarek, D.; Domaradzki, J.; Kepinski, L.; Chojnacki, K. Int. J. Photoenergy 2014, 2014, No. 463034. doi:10.1155/2014/463034

35. Xie, Y.; Yuan, C.; Li, X. Colloids Surf., A 2005, 252, 87-94. doi:10.1016/j.colsurfa.2004.10.061 
36. Nassoko, D.; Li, Y.-F.; Li, J.-L.; Li, X.; Yu, Y. Int. J. Photoenergy 2012, 2012, No. 716087. doi:10.1155/2012/716087

37. Kasim, A. Absorption and upconversion of $(\mathrm{Nd} 3+/ \mathrm{Er} 3+)$ doped tellurite glass. In 2012 IEEE Business Engineering and Industrial Applications Colloquium (BEIAC), Kuala Lumpur, Malaysia, April 7-8, 2012; IEEE Publishing: Piscataway, NJ, U.S.A., 2012; pp 38-42. doi:10.1109/BEIAC.2012.6226090

38. Khalid, N. R.; Ahmed, E.; Hong, Z.; Zhang, Y.; Ullah, M.; Ahmed, M. Ceram. Int. 2013, 39, 3569-3575. doi:10.1016/j.ceramint.2012.10.183

39. Raja, R.; Govindaraj, M.; Antony, M. D.; Krishnan, K.; Velusamy, E.; Sambandam, A.; Subbaiah, M.; Rayar, V. W.

J. Solid State Electrochem. 2017, 21, 891-903. doi:10.1007/s10008-016-3437-7

40. Liqiang, J.; Xiaojun, S.; Baifu, X.; Baiqi, W.; Weimin, C.; Honggang, F. J. Solid State Chem. 2004, 177, 3375-3382. doi:10.1016/j.jssc.2004.05.064

41. Balabhadra, S.; Debasu, M. L.; Brites, C. D. S.; Nunes, L. A. O.; Malta, O. L.; Rocha, J.; Bettinelli, M.; Carlos, L. D. Nanoscale 2015, 7, 17261-17267. doi:10.1039/c5nr05631d

42. Li, H.; Wang, G.; Zhang, L.; Huang, Y.; Wang, G. CrystEngComm 2010, 12, 1307-1310. doi:10.1039/B914641E

43. Tian, Y.; Tian, B.; Cui, C.; Huang, P.; Wang, L.; Chen, B. RSC Adv. 2015, 5, 14123-14128. doi:10.1039/C4RA13204A

44. Tobaldi, D. M.; Pullar, R. C.; Škapin, A. S.; Seabra, M. P.; Labrincha, J. A. Mater. Res. Bull. 2014, 50, 183-190. doi:10.1016/j.materresbull.2013.10.033

45. Araña, J.; Alonso, A. P.; Rodríguez, J. M. D.; Colón, G.; Navío, J. A.; Peña, J. P. Appl. Catal., B: Environ. 2009, 89, 204-213. doi:10.1016/j.apcatb.2008.11.027

46. Kongsuebchart, W.; Praserthdam, P.; Panpranot, J.; Sirisuk, A.; Supphasrirongjaroen, P.; Satayaprasert, C. J. Cryst. Growth 2006, 297, 234-238. doi:10.1016/j.jcrysgro.2006.09.018

47. Tryba, B.; Tygielska, M.; Colbeau-Justin, C.; Kusiak-Nejman, E.; Kapica-Kozar, J.; Wróbel, R.; Żołnierkiewicz, G.; Guskos, N. Mater. Res. Bull. 2016, 84, 152-161. doi:10.1016/j.materresbull.2016.07.035

48. Zhao, H.; Pan, F.; Li, Y. J. Materiomics 2017, 3, 17-32. doi:10.1016/j.jmat.2016.12.001

49. Mazierski, P.; Bajorowicz, B.; Grabowska, E.; Zaleska-Medynska, A. Photoreactor Design Aspects and Modeling of Light. In Heterogeneous Photocatalysis: From Fundamentals to Green Applications; Colmenares, J.; Xu, Y. J., Eds.; Springer: Berlin, Germany, 2016; pp 211-248. doi:10.1007/978-3-662-48719-8_7

50. Sobczyński, A.; Duczmal, L.; Zmudziński, W. J. Mol. Catal. A: Chem. 2004, 213, 225-230. doi:10.1016/j.molcata.2003.12.006

\section{License and Terms}

This is an Open Access article under the terms of the Creative Commons Attribution License

(http://creativecommons.org/licenses/by/4.0), which permits unrestricted use, distribution, and reproduction in any medium, provided the original work is properly cited.

The license is subject to the Beilstein Journal of Nanotechnology terms and conditions:

(https://www.beilstein-journals.org/bjnano)

The definitive version of this article is the electronic one which can be found at:

doi:10.3762/bjnano.9.43 